\title{
Attitude towards Teaching Career in Ten Years
}

\section{Liliana Bujor}

This study aims to capture the dynamic regarding the attitude of the first year students towards the teaching career. To identify the level of attitudes towards the teaching profession, we used a research method based on a questionnaire investigation, as method of analysis, and two different cohorts of students: cohort 1 was represented by students enrolled in 2010-2011 academic year and cohort 2 by the students enrolled in 2019-2020. The cohort, the environment and the gender gave us interesting results about the attitude towards teaching (total score, attitude towards others, work and self-attitude). The results showed that there are significant differences between cohorts in terms of attitude towards teaching career. So, we can say that there is a dynamic towards careers that must be integrated in educational policies and in the career orientation plans.

Keywords: attitude toward teaching, attitudinal dimensions, gender, environment.

\section{Problem statement}

According to Fishbein \& Ajzen's Theory of Planned Behavior (TPB), subjective attitudes and norms are predictors of intentions and behaviors. A person's attitude towards a specific behavior is conceptualized according to the consequences of the perception of that act and of the person's values (Cook, Lounsbury, Fontenelle, 1980). A large number of studies have explained attitude's influences by TPB (Gwernan-Jone, Burden, 2009). The behavioral aspect of attitude refers to the actions oriented directly towards the object of the attitude as well as to the intentions of action. According to certain authors, attitude is a hypothetical construct that represents an individual's like or dislike for an item and influences his interaction with the surrounding world (Fishbein, Ajzen, 1975). Attitudes of individuals towards their profession have an effect on their performance. In the teaching profession, perceptions and attitudes impact professional competences and achievement and play a significant role for a success's career. 
In order to be a good teacher, there is a set of requirements organised on three type of attitudes: (1) towards work, (2) towards others and (3) self-attitude in teaching career. If the future teacher develops a positive attitude towards this profession, would be much easier to form the abilities and competences that would be associated with the professional performance.

\section{Methodology}

\subsection{The objective of the paper:}

The study aims to identify the attitude towards teaching career of the first year students, enrolled in the psycho-pedagogical module, in the academic years: 2010-2011, 2019-2020, from the perspective of the dynamics conferred by the 10-year interval established between the two measurements.

\subsection{The hypotheses:}

1. The attitude towards the teaching career (total score, score on factors) presents significant differences depending on the academic year.

2. The attitude towards the teaching career presents significant differences depending on the environment of origin: urban, rural (for each cohort).

3. The attitude towards the teaching career presents significant differences depending on the gender (for each cohort).

\subsection{Research design and procedure:}

The Tool for Psychometric Evaluation of Student's Attitudes Concerning Teaching Career (SATC) (Schipor, Bujor, 2010) was applied in the first semester of the academic years 2009-2010 and 2019-2020 (October), during seminars of Educational Psychology.

The psychometric properties of the instrument are adequate to obtain statistically valid data: SATC fidelity is measured by the internal consistency - coefficient Alpha Cronbach, $\alpha=0.88$.

The tool measures the attitude towards the teaching career through 21 items, grouped in three dimensions: (1) the attitude towards others (e.g. my results in the work at the department would be better if I choose to collaborate with others than to work individually), (2) attitude towards work (e.g. teaching activity would bring me professional satisfaction) and (3) attitude towards self (e.g. I am more suitable than most people I have known for the teaching work). 
The self-report questionnaire allows obtaining a total score, and three separate scores for the different types of attitude, depending on the score given by respondents on a Likert-type scale, in 5 steps $(1$ - total disagreement, 5 - total agreement). The completion of the questionnaire took place in the pencil-paper version, without a time limit (average time 10 min.)

\subsection{Characteristics of the Study Population}

This study was attended by 336 first year students corresponding to the two academic years analyzed (1. 2010-2011, 2. 2019-2020). For cohort 1, assimilated to the academic year 2009-2010, we have 172 students $(51.2 \%)$, for cohort 2, represented by the academic year 2019-2020, we have 164 students $(48.8 \%)$. The distribution according to the environment of origin is approximately equal, 195 students (58\%) come from urban areas, $141(42 \%)$ from rural areas. The average age is $\mathrm{M}=20.62, \mathrm{SD}=4.97$.

\section{Results and Discussions}

\section{Results of the hypothesis 1}

The attitude towards the teaching career (total score \& factor score) presents significant differences depending on the academic year. The attitude towards teaching career (total score) presents significant differences between the averages of the two cohorts, $\mathrm{t}(335)=8,178, \mathrm{p}<0.001$; the mean of cohort $1(\mathrm{M}=$ 87.02 ; $\mathrm{SD}=.58)$ is significantly higher than the mean of cohort $2(\mathrm{M}=$ 80.33; SD = .56).

The attitude towards teaching career (score on the scale the attitude towards others in teaching activity) presents significant differences depending on the analyzed cohort. Attitude towards teaching career (score on the scale attitude towards the others in the didactic activity) presents significant differences between the averages of the two cohorts, $\mathrm{t}(335)=24.79, \mathrm{p}<0.001$; the mean of cohort 1 is significantly higher $(\mathrm{M}=37$; $\mathrm{SD}=3.81)$ than the mean of cohort $2(\mathrm{M}=$ 27.41 ; $\mathrm{SD}=.26$ ).

The attitude towards teaching career (score on the scale the attitude towards work) presents significant differences depending on the academic year. Attitude towards teaching career (score on the scale attitude towards work in the teaching activity) presents significant differences between the averages of the two cohorts $\mathrm{t}(335)=-5.13, \mathrm{p}<0.001$; the average of the cohort 2009-2010 is significantly lower $(\mathrm{M}=25.34$; $\mathrm{SD}=.25)$, compared to the average of the cohort 2019-2020, $(\mathrm{M}=27.38$; $\mathrm{SD}=.30)$.

The attitude towards didactic career (score on the scale the self-attitude) presents significant differences. Attitude towards the teaching career (score on the 
scale self-attitude) presents significant differences between the averages of the two cohorts $\mathrm{t}(335)=-33.22, \mathrm{p}<0.001$; the mean of cohort 1 is significantly lower $(\mathrm{M}=16.47$; $\mathrm{SD}=.15)$ than the mean of cohort $2(\mathrm{M}=25.55$; $\mathrm{SD}=$ $.23)$.

\section{The results of the hypothesis 2}

The attitude towards teaching career presents significant differences depending on the environment (for each of the two cohorts).

By measuring the direct and interaction effects, we found that the environment does not determine significant differences between the students of the two cohorts in terms of attitude towards the teaching career (total score and score on the three scales);

The attitude towards the teaching career is influenced only by the cohort, not by the environment. We do not have a significant interaction effect, $\mathrm{F}(1)=.775, \mathrm{p}=.379$ of the two independent variables taken simultaneously (cohort and environment) on the dependent variables attitude towards teaching career, total score (Fig. 1).

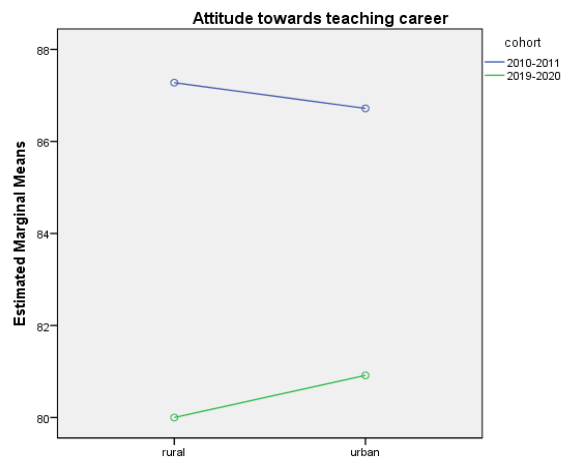

Fig. 1

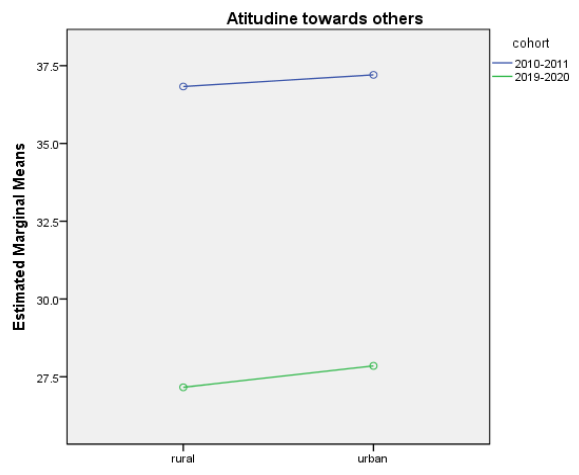

Fig. 2

We do not have a significant interaction effect, $\mathrm{F}(1)=.156, \mathrm{p}=.693$ for two independent variables taken simultaneously (cohort and environment) on the dependent variables attitude towards others in the teaching career (Fig. 2). Neither for the attitude towards work, F (1) $=.570, \mathrm{p}=.414$, respectively the attitude towards self, $\mathrm{F}(1)=.817, \mathrm{p}=.367$, there is no interaction effect, the cohort remaining the only independent variable that influences the attitude towards teaching career.

It is interesting that, for these three types of attitudes, the hierarchy of scores changes: cohort 2 values less the teaching career (total score) and the teaching career reporting to work with others, instead, students in the 
last academic year focus more on work and self in teaching career (Fig. 3, Fig. 4).

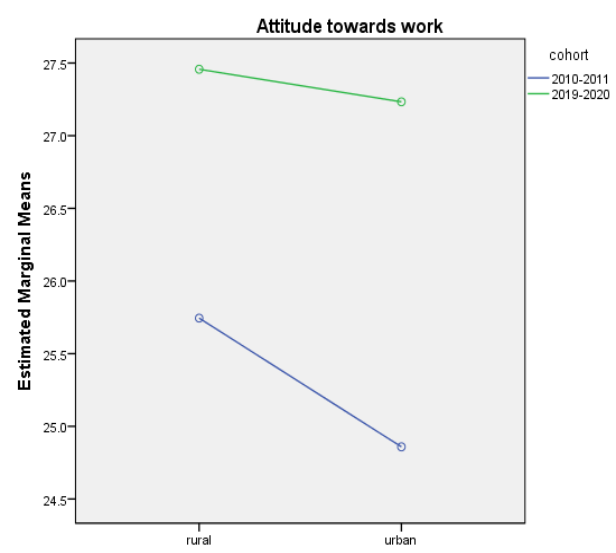

Fig. 3

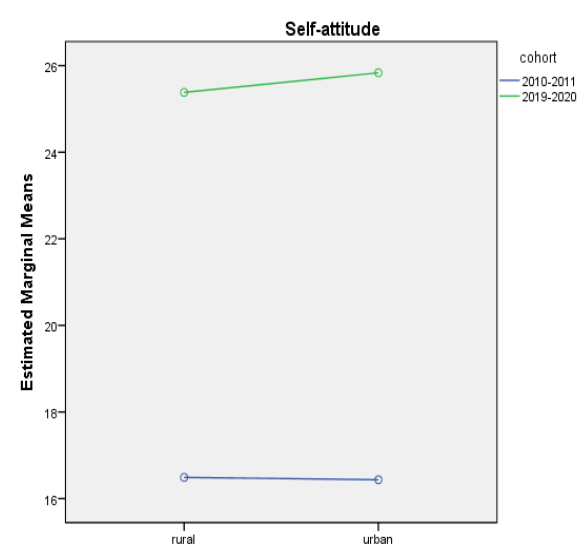

Fig. 4

\section{The results of the hypothesis 3}

The attitude towards teaching career presents significant differences depending on the gender (for each cohort).

By measuring the direct and interaction effects, we find that gender determines significant differences between the students of the two cohorts in terms of attitude towards teaching career only for the subcomponent attitude towards work; F (1) $=9.329, \mathrm{p}=.002$ (Fig. 7). Instead, we have no interaction effects between gender and cohort, the only one that influences the attitude towards the teaching career: total score, $\mathrm{F}(1)=.022, \mathrm{p}=.883$, (Fig.5), the attitude towards the others, $\mathrm{F}(1)=.000, \mathrm{p}=.983$ (Fig.6), selfattitude $\mathrm{F}(1)=.009, \mathrm{p}=.361$ (Fig.8) being the cohort. 


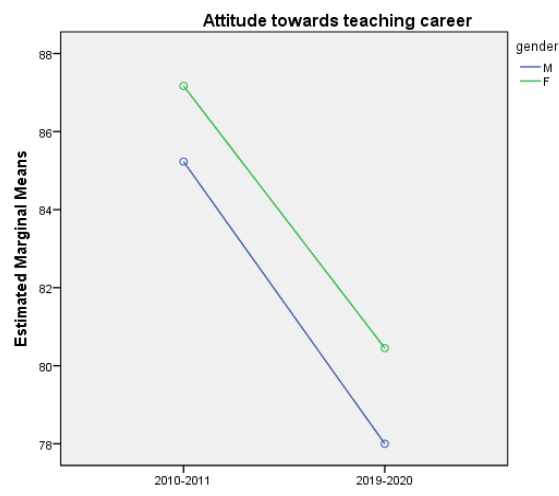

Fig. 5

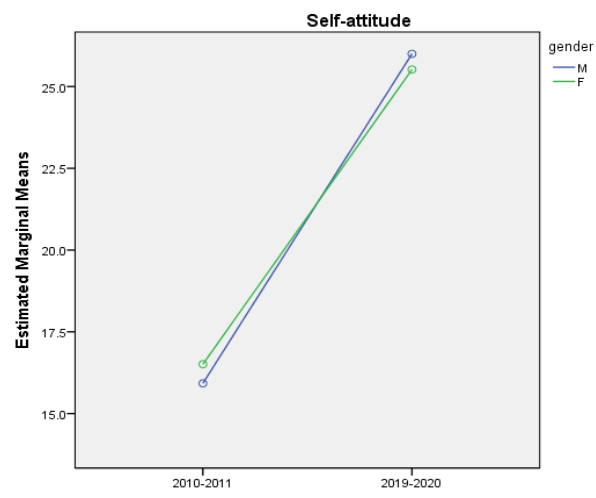

Fig. 7

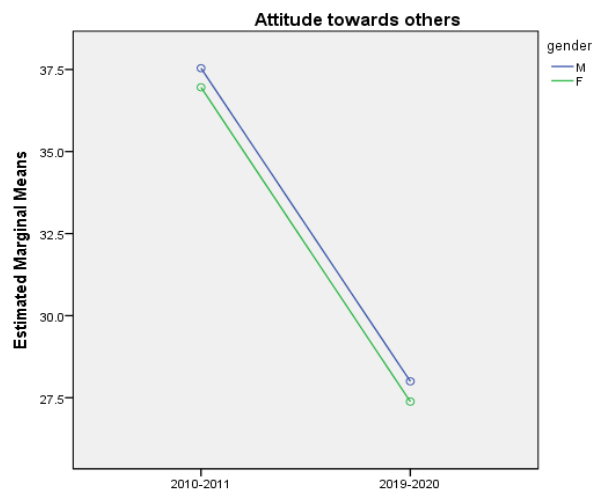

Fig.6

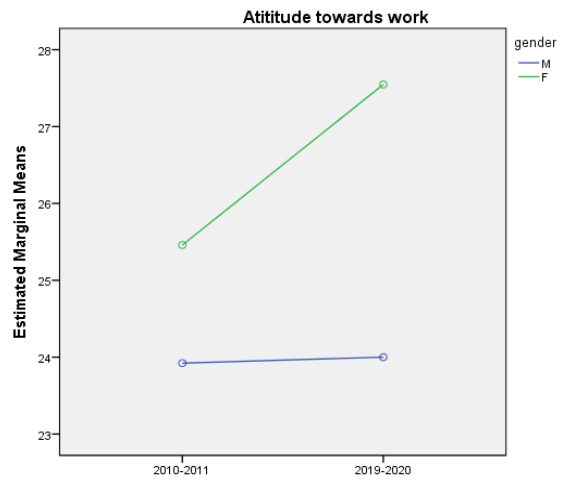

Fig. 8

\section{Conclusions}

The independent variables taken in consideration (cohort, environment and gender) influence the attitude towards the teaching career. The students of first cohort express a more positive attitude towards the teaching career and they focus on others (the actors of educational process), more than on themselves. The results are consistent with those of other studies: there is a negative perspective regarding the teaching profession sustained by the fact that the respectability of the teaching profession has been disregarded (Gun, 2012). Contrary, the actual students see the teaching career more like a personal opportunity and they are more interested in the teaching career in relation with themselves and with their own activity. The future teachers, although their beliefs and their affective experiences regarding the teaching 
career are associated with positive values, they do not equally manifest the intention to exercise the associated behaviors (Andronache et al., 2014).

Because the teaching activity is a social profession, with a major implication on the qualitative relationships, we consider that our results can be valued in organizing teacher training programs emphasizing on the preoccupation for interactions, relationships and mutual exchanges. Gender doesn't lead to differences, except regarding attitude towards work. The girls are more assumed and express this attitude in terms of behaviors. We know that, in general, the teaching activity is considered to be more like a woman's activity. Thus, we can explain these significant differences through the existence of a gender stereotype related to this professional activity.

In conclusion, it is worth mentioning that the formation of future teachers' attitude is a must do during a psycho-pedagogical training. Developing a correct attitude towards self, others and work can be considered a tridimensional approach with major implications on the career performance in general, and for the teaching activity in particular.

\section{References}

Andronache, D., Bocoş, M., Bocoş, V., Macri, C. (2014). Attitude towards teaching profession. Procedia - Social and Behavioral Sciences, 142, 628 - 632.

Cook, M., Lounsbury, J., W., Fontenelle, G., (1980). An application of Fishbein and Ajzen attitudes subjective norms model to the study of drug use. The Jornal of Social Psychology, 110, 193-201.

Gwewnan-Jones, R., Burde, R. (2009). Are they just lazy? Student teachers'attitudes about dyslexia. Dyslexia.

Gun, S. (2010). Attitudes of primary school teacher candidates towards the teaching profession. Procedia - Social and Behavioral Sciences, 46, 2922 - 2926.

Fishbein, M., Ajzen, I. (1975). Belief, Attitude, Intention, and Behavior: An Introduction to Theory and Research, Addison-Wesley.

Schipor, D., M., Bujor, L., (2011). Building a Tool for Psychometric Evaluation of Student's Attitudes Concerning Teaching Career. Procedia- Social and Behavioral Sciences, 11, 281-285. 